\title{
1. Competitiveness and national technology systems: an introduction
}

This book analyses national technology systems supporting manufacturing in five African economies: Kenya, Tanzania, Uganda, Ghana and Zimbabwe. The first reaction of many readers is likely to be as follows. 'Why look at industrial technology systems in Africa? Surely industrial development at this level does not need a "technology system"? And, given the rather parlous state of manufacturing in these countries, doesn't technological effort take fairly low priority?' The contention here is that 'technology' is vital to industrialization at all levels. This has always been so - but the new technological and competitive environment makes it even more important, and in many ways more difficult, to build the local capabilities needed. Technology 'systems' (the term is defined below) are vital to building industrial capabilities at the enterprise level - and such systems are extremely weak and fragile in most African countries. What is worse is that they are neglected and so are increasingly lagging behind technology systems in competing countries. The structural base of African industrial development is thus being weakened, and this should be an important consideration for development strategy in the region.

The analysis seeks to illustrate the technology situation in African countries at different levels of industrialization. It draws upon fieldwork done in a fairly short period in each country. It cannot, therefore, provide detailed institutional analysis - the intention is more to describe the 'technology system' in broad comparative terms and to suggest directions of policy reform. Given the relative neglect by researchers of this subject, even a study of this sort is useful: little is known about the nature of technology systems in Africa (an important exception is Enos, 1995).

The remainder of this chapter spells out the analytical framework for the empirical analysis. Chapter 2 provides some background on the competitive performance of manufacturing industry in Sub-Saharan Africa relative to other developing regions. Chapters 3 to 7 deal with technology systems in the selected countries, and make policy recommendations to strengthen the systems in each. An Annex treats an important related issue: the attraction of foreign direct investment (FDI) in manufacturing to Africa, with a focus on export-oriented activities. 


\section{THE PREMISES}

Despite its disappointing performance in the last decade, industry remains vital to growth, employment and structural change in Sub-Saharan Africa. Manufacturing is still the main engine for transforming the economic structure of low-income countries, letting them shift from slow-growing, low-return activities to activities with high productivity and strong growth potential (Chenery et al., 1986). It is the most potent user and carrier of technology to the economy, the main agent for the creation, transfer and application of new technologies. It provides the hardware of production (machinery) to all economic sectors and catalyses new methods of management, organization, ownership, financing and governance. It creates new jobs, skills and entrepreneurship, and often promotes social mobility. It is a powerful magnet for attracting foreign resources. It can play a vital role in upgrading agriculture and services, providing new inputs, knowledge and skills as well as new demand for their products. It stimulates the development of new institutions and legal structures.

If we accept that revitalization of industrial growth will be a crucial element in African development, we should also bear in mind that, with rapid technical change, globalization and policy liberalization, the context for industrial development is changing radically. It is becoming imperative for enterprises (whether they serve domestic or foreign markets) to be internationally competitive. Many things matter for competitiveness, but one of the most important is the ability to access new technologies, deploy them efficiently, and improve them in line with technical change. This ability cannot be taken for granted and it is not easily acquired, even in countries with simple industrial sectors that rely heavily on imported technologies. African enterprises may not need to create new technologies; they do need to build capabilities, organizations and industrial structures to master, adapt and improve on foreign technologies. All the evidence suggests that these elements are deficient in Africa, even in comparison with other developing regions (Biggs et al., 1994, 1995; Lall, 1995, 1999; Lall et al., 1994; Pietrobelli, 2001).

Building industrial capabilities in developing countries is often a difficult, prolonged, costly and risky task. Since it faces numerous market and institutional failures, it cannot be assumed that efficient capabilities will arise automatically in response to liberalization of trade, technology and foreign direct investment (FDI) policies. Rapid liberalization with a weak base of capabilities can devastate industrial enterprises, as they are exposed to competition from firms with much stronger capabilities. Opening up to inflows of technology and FDI does not mean that they will come to economies without the complementary capabilities needed to make them technically efficient. Yet much of liberalization in Africa seems to have been 
premised on the assumption that capabilities do not matter or will arise by 'getting prices right'. One economy after another is exposing their industries to global market forces without any strategy or effort to discover capability needs and meet those needs. As a result, there has been considerable hardship, dislocation and closure in industry (Lall et al., 1994; Lall, 1999c), and few signs of the emergence of competitive new manufacturing activities.

Industrial capabilities develop largely within individual enterprises, but the pace and depth of this development depend significantly upon the economic, policy and institutional environment in which the enterprises operate. Firms do not build capabilities in isolation but in close interaction with each other, factor markets and support institutions, and in response to signals arising from markets and policy-makers. Many of these elements have systematic relations with each other and so are described as forming a 'technology system'. Weak systems lead to deficient capabilities, the inability to use technology effectively and so to uncompetitive firms. The causation also runs the other way around: technologically slothful firms do not demand strong support systems and do not feed into technological effort by other firms and institutions. This book deals, not with the entire technology system, but with the main institutions involved in technology import, creation and diffusion.

\section{THE COMPETITIVENESS CHALLENGE}

International competitiveness has always mattered for industrial growth, though its significance has varied by country and stage of development. Most countries - including the mature industrial powers today - launched industrialization behind protective barriers, but the extent and duration of protection varied. The early industrializers (in Europe and North America) enjoyed fairly high levels of 'natural' protection from foreign competition arising from high transport costs, poor communications and differing demand patterns. Policy-imposed protection was, nevertheless, also significant. High import tariffs, widespread quantitative restrictions and more subtle barriers (for example from bans on equipment export and migration, government procurement or technical standards) were common among industrial economies (Reinert, 1995). And this was at a time when competitive gaps in technology, skills and institutions were relatively small.

The post-Second World War period saw a widespread dismantling of trade barriers in the mature countries. It also saw the launching of a deliberate development strategy in the developing world, generally with the promotion of industrialization behind high barriers to import competition. In part this strategy was a reaction to the liberal trade and investment setting of the colonial era, when little industrial development took place. In part it reflected 
development thinking at the time, with a strong emphasis on planning and other forms of strong government intervention. For several decades thereafter manufacturing industry in most developing countries grew with little or no exposure to international competitive pressures.

There were some exceptions. A few developing countries - entrepôt centres, tax havens and small industrializing economies like Hong Kong and Singapore - maintained liberal trade regimes. Of these, only the two economies mentioned were able to build large and competitive industrial sectors, the former because of unique initial conditions and the latter by virtue of pervasive industrial policy (Lall, 1996). Some others, most notably Korea and Taiwan, succeeded dramatically by combining import protection and other forms of industrial policy with export orientation, forcing their enterprises to compete in global markets (ibid.). By contrast, the vast majority of developing countries, including those in Africa, sheltered their industries for long periods, their governments often owning firms and directing resource allocation. Many countries also restricted inflows of technology via FDI, licensing and capital goods. One result, now universally accepted, was the fostering of technical inefficiency, technological lags, poor capabilities, and uncompetitive firms.

This setting is changing rapidly and irreversibly as industry the world over moves into a more open environment. Part of the reason is technological. New transport, communication and information technologies are reducing natural protection, forcing economies closer together and spreading demand patterns. Industrial firms are increasingly transnational, taking their operations into the domestic markets of most countries and confronting domestic firms with direct competitive pressures. Part of the reason lies in policy reform. Governments are (willingly or reluctantly) removing interventions in trade and investment, disillusioned with import-substitution policies and state ownership, or giving in to powerful external pressures. Whatever the reason, most remaining policy barriers are set to disappear. Africa is part of this trend, and its industrial firms will face the global competitive economy more or less openly by 2010 .

Needless to say, in this setting industrial growth - and indeed survival - in every country will depend on the ability of its enterprises to compete fully with international counterparts. Some new forces make it easier to become competitive: market signals are clearer and stronger, and technology is more mobile than ever before. Transnational companies (TNCs) are growing in size and spread, transferring new technologies across the world with unprecedented speed and effectiveness (UNCTAD, 1999a). Similarly, many technologies are also readily available to local firms (in the form of capital goods, licensing, consultancy or subcontracting). Other forms of information also flow far more easily and cheaply, making it possible for enterprises to 
access new markets, technologies and collaborators.

At the same time, some forces make it more difficult to achieve industrial competitiveness. The technological demands of efficiency are rising apace, with a host of new skill, organizational and institutional needs, and the rate of change is accelerating (Lall, 2001a). Some technologies and markets are more effectively controlled by giant TNCs, who are unwilling to part with them without taking a large equity stake. There are limits to the involvement of developing countries in the globalization of technology (Archibugi and Pietrobelli, 2001). Many of the tools of industrial policy apart from import restrictions (local content rules, export subsidies, directed credit, reverse engineering and so on) are being constricted or forbidden by international rules and agreements.

The pace and ubiquity of technical progress mean that all activities have to improve their technologies and the skills needed to operate them if they are to compete. With the liberalization of trade and investment, even non-traded activities are increasingly exposed to international competition, and have to improve their competitive base to survive and grow. Skill needs rise with the level of development, but even the least developed countries have to improve their human capital base if they are to grow and prosper. To quote ILO (1998, p. 32),

In both developed and developing countries, employment of skilled workers has been on the rise ... The rate of growth of employment in the period 1981-96 in advanced countries has usually been highest for professionals and technicians... In developing countries, too, this occupational category has witnessed a high growth rate, though one less disproportionate to other categories in comparison to developed countries. In contrast, the rate of growth of employment for the production and related workers category (which contains skilled manual and craft workers but mainly the unskilled and semi-skilled) has been very low, often negative, for developed countries. In the developing countries for which data are available, with some exceptions (e.g. Philippines), this group has witnessed much lower employment growth than the highly educated and trained group of professionals and technicians.

Maintaining a competitive edge with rising wages requires advanced skills, even in simple labour-intensive activities. For instance, in the clothing industry, it requires sophisticated design, quality control, layout, delivery and so on as product cycles become shorter and more reliable, and high quality and rapid delivery become vital to winning orders. In fact, the skill needs of high value added activities in labour-intensive industries may be even more demanding where automation is possible. Skills are, moreover, subject to constant change. Thus,

the demand for professionals and technicians has increased in all countries, as their 
analytical, cognitive and behavioural skills equip them better to adapt to more sophisticated technology. However, even within these high-skilled jobs the trend is increasingly towards multi-skilling - combining specialised professional expertise with business and management skills ... [Even for production workers] the trend is towards up-skilling and multi-skilling. A study of 56,000 production workers over an eight-year period shows that skill requirements in production jobs have changed across the board. It is not only that each job has experienced up-skilling, but the overall distribution of production jobs has shifted away from the less skilled to the more skilled. (ILO, 1998, p. 47)

Analysts like Best (1990) note that the nature of competition itself is changing. Traditional modes of competition, based on low costs and prices, are being replaced by 'the new competition' driven by quality, flexibility, design, reliability and networking. Firms are specializing increasingly in different segments of the production chain, outsourcing processes and services to reap economies of scale and specialization. Tapping information flows and networking, very skill-intensive functions, are the new weapons in the competitive armoury. As much as 50 per cent of the value of a new car now lies in its 'information content' - design, process management, marketing, sales and so on. As The Economist (1996, p. 48) noted, 'over three-quarters of the value of a typical manufactured product is already contributed by service activities such as design, sales and advertising'. The rise in the share of high value services strengthens this trend.

While Africa faces the same international context as other regions, the fact that it is the least developed industrially exacerbates the competitive challenge. Import substitution has provided African enterprises with the smallest base of industrial capabilities. Its technology base is the lowest, its attractiveness to manufacturing TNCs the weakest and its ability to respond to world market opportunities the most constricted. Its enterprises have furthest to go in building basic competitive capabilities. Thus, liberalization is likely to have the most damaging effects in Africa. The structural weaknesses are taken up in the next chapter; let us now consider why capabilities are necessary.

\section{THE NEED FOR INDUSTRIAL 'CAPABILITIES'}

Much of the conventional policy literature in development assumes away the need for industrial capabilities as a determinant of industrial success, by presuming that 'latecomers' can simply import appropriate technologies from advanced countries and use them in production without further effort, cost or risk. If technology were transferable like a physical product (that is, embodied in equipment, patents and blueprints), then indeed no further learning or capabilities would be called for - getting prices right would ensure that 
developing countries optimized their technological choice and use. Industrial capacity (the physical plant) becomes equivalent to industrial capabilities.

A large body of empirical research on developing countries suggests that this depiction is over-simplified and misleading (for summaries see Lall, 1992a, 2001a; Pietrobelli, 1997). Based on the evolutionary tradition pioneered by Nelson and Winter (1982), it argues that firms do not have a clear knowledge of the available set of technologies or of how to operate any new technology efficiently. Finding the right technology at the right prices involves cost and risk (particularly in a developing country). Using the technology involves further effort: search, experimentation, induction of new information and learning. Making the technology work efficiently under new conditions involves further effort, to adapt it to local demand, scales of production, worker skills and raw materials (Battisti and Pietrobelli, 2000). Technologies, in other words, have large 'tacit' elements that have to be mastered by the recipient and cannot be sold by the technology supplier like a physical product. Without considerable additional effort to learn various aspects of the technology, no enterprise can reach the levels of efficiency required to compete in world markets.

Technological effort does not end with mastering a given version of the technology. All technologies can be improved by minor adjustments, which calls for further effort and new capabilities. If the international frontier in the technology shifts - it always does - firms have to induct and master the new versions to stay competitive. As technologies in use grow more complex and involve new skills and larger scales of production, formal research and development (R\&D) often becomes necessary, not so much to recreate the technology as to monitor, understand, adapt and improve it. Much of R\&D, even in developed countries, is used to keep track of, copy and adapt innovations outside the firm (Cohen and Levinthal, 1989). In developing countries, the main function of R\&D is to master, adapt and improve imported technologies; only at some relatively mature stage does it become truly innovative.

While using any new technology involves building new capabilities, the degree of uncertainty and difficulty varies according to the technology and, within it, the specific functions undertaken. The more complex the technology involved, and the more advanced the functions undertaken, the more difficult it is for a newcomer to build the capabilities. How difficult it is depends on three things: the initial capabilities of the enterprise, the support it can draw upon from its environment, and the novelty of the technology relative to its existing stock of knowledge. The same technology may be almost costless to absorb for a firm in a relatively industrialized country but very costly and difficult to master for a firm in an unindustrialized one.

These efforts can occur almost anywhere in the firm, on the shop floor, in 
process or product engineering departments, procurement or marketing, or R\&D. In-house efforts can draw upon information, assistance and skills from outside. In fact, a great deal of technological information comes from other firms: equipment and material suppliers, contractors, competitors or buyers (particularly foreign buyers). Some comes from institutions like technical extension services, technology institutions, universities or financial intermediaries. Then there are informal sources of information like trade fairs, conferences, journals and the like. Ultimately, however, capability building is a collective action within the firm: to be effective, it has to involve the whole firm and be accessible to all its members. A few skilled technicians or engineers do not make for a capable and competitive enterprise. A very similar process of capability building occurs in non-technical functions like marketing, procurement, training or financial management. Technical and other processes have to interact with each other, since building capabilities involves changing institutional processes or routines and launching new ways of managing information and people (Nelson and Winter, 1982).

The way in which knowledge is used differs, of course, by the level of development. In mature industrial countries, the competitive use of technology is largely a matter of innovation - the ability to create new products and processes. In developing countries, innovation is less important than the ability to use and adapt existing technologies at competitive levels of cost and quality. How difficult this is and how long it takes depends on the country and the technology, but learning is always necessary. Even routine capabilities, say for quality management or process optimization, take years to build in industrial newcomers. More advanced capabilities, for modifying, improving or generating technologies, can take longer to build. The pattern of industrial success in the developing world reflects to a large extent the effectiveness with which countries have undertaken learning (Lall, 1996; Pietrobelli, 1994b). Some have reached the frontiers of advanced technologies, and are competing with mature countries on their home turf. At the other extreme, many, as in Africa, have not been able to build even the basic operational capabilities needed to compete internationally in simple technologies.

The rise of globalized production under the aegis of TNCs reduces the need for building domestic capabilities in some ways. Since TNCs provide affiliates with intangible assets (skills, technology, production expertise, training and so on), the host economy needs to offer correspondingly fewer 'ready-made' capabilities and invest less in subsequent absorption. Considerable industrial and export growth has taken place on this basis in countries with relatively low local technological capabilities. The growth of global production systems does not, however, do away with the need for local capabilities (see Guerrieri et al., 2001, on the complementarity between local and global capabilities). The countries that have attracted export-oriented FDI have offered a base 
of basic skills and infrastructure for simple manufacturing operations. Subsequent upgrading into more complex activities has involved investments in skill and institution building, supplier development and modern infrastructure.

The diffusion of TNC technology to local enterprises has also involved strong support for developing their technological capabilities. The transfer of the most advanced functions like R\&D has only taken place in host countries that have advanced capabilities and research institutions. In other words, FDI can reduce the need for local capabilities and institutions in the early stages and for very simple activities. Beyond this stage, countries still need to build local capabilities. In any case, there are many industries where TNCs are not very active. African countries in particular cannot rely on foreign firms to lead growth in a range of simple processing activities using low technologies at small scales of production. There is no alternative to building local capabilities in these activities. Finally, there is the fact that all countries, even the least developed, have a myriad of small and micro enterprises in existence. These have to be helped to survive and grow: in the new competitive environment this necessarily involves the building of new capabilities.

\section{NATIONAL TECHNOLOGY SYSTEMS}

We noted that firms do not learn or innovate on their own but in intense interaction with other firms, factor markets, support institutions and governments. They respond to rules on trade, competition, employment, intellectual property or the environment, and they behave in ways fashioned by their history, culture and environment. The interaction of economic, social and political factors provides the system within which firms learn and innovate, and so compete in global markets. There is a substantial recent literature on 'national innovation systems' which deals with these systemic aspects of technological performance, focusing mainly on the creation of new technologies in advanced industrial economies (Lundvall, 1992; Nelson, 1993; Edquist, 1997).

Similar systemic considerations apply to developing countries, where frontier innovation is not important but other forms of technological effort are. Technological effort is similarly embedded in the specific economic, policy and institutional context of each country. We use the slightly different term, 'national technology systems', to describe the environment within which developing countries build industrial capabilities. The idea is very similar to the 'national innovation system', but in developing countries the emphasis is different. There is greater stress on the incentive regime (like trade and competition policies, which differ more than in developed countries) and 
market and institutional failures in learning (again more pervasive and stringent than in developed countries).

What determines the effectiveness of national technology systems? In the simple neo-classical world that informs most development analysis, firms optimize under free market conditions by choosing, from a known array, the techniques appropriate to their relative factor prices and costlessly using these at 'best practice'. In an evolutionary world like the one posited here, with complex learning processes and externalities, the ability to select and deploy technologies efficiently cannot be taken for granted in this way. Many requirements of learning involve serious market failure. It cannot be assumed that over time enterprises will move automatically and efficiently into more difficult technologies (or taking on more complex tasks) in response to changing prices and factor endowments. Technological upgrading and deepening requires enterprises to invest in more advanced - and so more costly, uncertain and prolonged - learning processes. In the presence of externalities and deficient factor markets, such investments will be deficient in free markets. Policy interventions are then needed to overcome market failures - to tackle learning costs, promote externalities and linkages, coordinate factor market improvements with needs, and develop institutions. In the final analysis, therefore, national technology systems depend on the effectiveness of industrial policy.

The general trade and other policy needs of industrial development have been extensively debated in the literature and it is not relevant for us to review that debate. Our focus is on two aspects of national technology systems: technology policies in the narrow sense and technology institutions. Technology policies cover such areas as technology import by licensing and FDI, incentives for local R\&D and for training. 'Technology institutions' are used here in the narrow sense to refer to bodies such as quality, standards, metrology, technical extension, $R \& D$, and technology training. They may be government-run, started by the government but run autonomously, or started and managed by industry associations or private interests. The technology literature (for instance, country studies in Nelson, 1993) stresses the significance of such institutions for supporting enterprise efforts to innovate and build capabilities. Mowery and Rosenberg (1989) describe the historic evolution of technology policies and institutions in mature industrial countries, in particular in the USA.

The technology institutions analysed here include those for $M S T Q$ (metrology, standards, testing and quality), public research and university research concerned with industry, and technical support and extension for SMEs. Many of their services are the essential 'public goods' of technological effort, difficult to price on market terms. Public research institutes and universities undertake basic research that does not yield commercial results in 
the short term, but provides the long-term base of knowledge for enterprise effort. Quality, standards and metrology institutions provide the basic framework for firms to communicate on technology and keep the basic measurement standards to which industry can refer. Extension services help overcome the informational, technical, equipment and other handicaps that SMEs tend to suffer. The provision of these services faces market failures of the sort that every government, regardless of its level of development, has to remedy.

\section{CONCLUSIONS}

Africa needs to industrialize but in the near future it will have to do this in a much more demanding setting than in the first bout of industrialization. Most of its enterprises will face the full force of international competition, with aggressive firms from other low-wage developing countries seeking to penetrate their domestic markets and keep them out of export markets. Their competitors will often have higher levels of skill, stronger technological capabilities, denser supply networks and better physical and institutional infrastructure than they do. To compete with these firms in a world of pervasive and rapid technical change, African firms will need a much more advanced and broad-based set of skills and capabilities.

Simply liberalizing on trade, getting the macroeconomic and political situation right, promoting FDI and domestic competition will not be enough to meet these needs and to catalyse the flagging industrial sector. There is a need for comprehensive and proactive policies to build industrial capabilities, and without using traditional tools of policy like protection and subsidization. The brunt of future needs has to be met by technology and skill-creating institutions acting on the 'supply side' of industry.

All African countries have most of the necessary institutions in name. Most have copied the institutional structures of former colonial powers, the UK in the case of our sample countries. The dynamic Tiger economies of East Asia have very similar institutional structures, charged with similar functions. How effective in comparison are the African institutions? Are they capable of meeting the technological needs of the firms they serve in the new global setting? How can they be improved?

These are some of the questions which subsequent chapters try to answer. 